\title{
Guia-avaliativo de português como língua adicional para crianças estrangeiras bilíngues
}

\author{
Evellyn GASPARELLO (D) \\ Universidade Tecnológica Federal do Paraná (UTFPR)
}

\section{○}

OPEN ACCESS

Jeniffer Imaregna Alcantara de ALBUQUERQUE (1)

EDITADO POR

Universidade Tecnológica Federal do Paraná (UTFPR)

- Luiz Amaral (UMASS)

- Ricardo de Souza (UFMG)

- Thaís Maíra de Sá (CEFET-MG)

AVALIADO POR

- Josiane Marques da Costa

(UFLA)

- Denise Weiss (UFJF)

SOBRE OS AUTORES

- Evellyn Gasparello

Escrita - análise e edição.

- Jeniffer Imaregna Alcantara de

Albuquerque

Escrita - análise e edição.

DATAS

- Recebido: 15/10/2020

- Aceito: 11/12/2020

- Publicado: 23/12/2020

\section{COMO CITAR}

Gasparello, E.; Albuquerque, J. I.

\section{RESUMO}

Nosso trabalho se insere na esteira de contribuições acerca do crescimento dos fluxos migratórios de estrangeiros no Brasil e seus processos de migração e de aprendizagem do Português Brasileiro como Língua Adicional. Famílias estrangeiras chegam ao Brasil e, além de se adaptarem ao novo contexto social, precisam se estabelecer em vários aspectos, sendo que um deles é a garantia de continuidade da educação de seus filhos. Devido à escassez de materiais didáticos voltados para a avaliação do desenvolvimento linguístico de crianças migrantes bilíngues, o presente trabalho tem como objetivo a apresentação e a descrição do processo de elaboração de um guia-avaliativo para este público. Tal motivação ocorreu após uma entrevista com mães de duas nacionalidades distintas sobre suas considerações em relação ao ingresso de seus filhos em escolas brasileiras. Visando atender o objetivo, baseamos as orientações do guia-avaliativo em materiais de avaliação para o contexto bilíngue. Como próximo passo, nos baseamos no guia elaborado por McLaughlin et al (1995) para construir uma versão, em português, das orientações acerca da avaliação de crianças bilíngues. Nesta adaptação, foi considerado o contexto social das instituições brasileiras para que o guia fosse apropriado a esta realidade. Como resultado, foi obtido um guia prático para a avaliação do desenvolvimento linguístico de crianças estrangeiras bilíngues no Brasil. O 


\section{REVISTA DA ABRALIN}

guia é composto por cinco etapas a serem seguidas pelos avaliadores das escolas e propõe, ao final, medidas estratégicas que auxiliem no desenvolvimento das línguas, tanto materna quanto adicional, dessas crianças.

\section{ABSTRACT}

This work is part of the research agenda on the growth of migratory flows of foreigners in Brazil and their migration and learning processes of Brazilian Portuguese as an Additional Language. Foreign families arrive in Brazil and, in addition to adapting to the new social context, they need to establish themselves in several aspects, one of which is to guarantee the continuity of their children's education. Due to the scarcity of teaching materials to evaluate the linguistic development of bilingual migrant children, the present work aims at presenting and describing the process of an evaluation guide developed for this target audience. The motivation occurred after an interview with three mothers of different countries about their considerations regarding their children's entry into the Brazilian's schools. In order to achieve the objective, we based our tutorial's guidelines in evaluation materials in the bilingual context. Afterwards, we used the guide developed by McLaughlin et al (1995) to build up a Portuguese version of the guidelines for the assessment of bilingual children. In this adaptation, the social context of Brazilian institutions was considered, so that the tutorial was appropriate to this reality. As a result, a practical tutorial was obtained to assess the language development of bilingual foreign children in Brazil. The tutorial consists of five steps to be followed by school evaluators and it proposes, at the end, strategic measures to assist in the development of languages, both of the mother tongue and the additional language, for these children.

\section{PALAVRAS-CHAVE}

Avaliação. Material didático. Português como Língua Adicional.

Crianças bilíngues.

\section{KEYWORDS}

Evaluation. Didactic Material. Portuguese as an Additional Language. Bilingual Children. 


\section{REVISTA DA ABRALIN}

\section{Introdução}

Atualmente, a população brasileira observa a presença de um grande fluxo migratório em todo o seu território. Segundo dados do Alto Comissariado das Nações Unidas para Refugiados ${ }^{1}$ (ACNUR, 2016) e de informações do observatório de Migrações, providas por Oliveira (2016), há um maior índice migratório para a região Sul do Brasil, principalmente para as capitais Curitiba, Florianópolis e Porto Alegre. O processo migratório trouxe consigo a necessidade emergencial de se aprender o Português Brasileiro (na modalidade de língua adicional), uma vez que é por meio da língua que o processo de (re)construção identitária e de acessibilidade a bens materiais (materiais de consumo, imóveis e dinheiro) e bens simbólicos (língua, educação e amizades) será realizado (NORTON, 2013). Em um primeiro momento, a procura pelo aprendizado da língua era maior entre a população adulta. No entanto, com o passar do tempo, a emergência de aprendizado do PB aumentou entre a comunidade de filhos dos migrantes, crianças na faixa etária de 5 a 16 anos. Frente a essa nova demanda, a rede pública de ensino passou a acolher essas crianças no sistema educacional brasileiro. No entanto, as instituições de ensino não estavam adaptadas para que se pensasse em um processo de aprendizado do PB como língua materna (para as crianças brasileiras) e, ao mesmo tempo, para falantes de outras línguas (para crianças migrantes providas, principalmente, do Haiti, Síria e Venezuela). Assim, na tentativa de entender um pouco mais sobre a inserção dessa comunidade no ensino regular, este artigo se debruça sobre a análise das adaptações que passam a ser feitas no processo avaliativo do Português para Falantes de Outras Línguas ${ }^{2}$ (PFOL).

Para tanto, o presente trabalho possui como objetivo a apresentação e a descrição do processo de elaboração de um guia-avaliativo para crianças migrantes que ingressam no ensino público brasileiro. Chamamos a atenção para o fato de que, como será descrito posteriormente na seção de metodologia, a aplicação e a avaliação do guia elaborado não foram possíveis devido à pandemia da COVID-19. Nesse sentido, este trabalho tem como foco as etapas de elaboração do instrumento, não se caracterizando como uma análise de um instrumento avaliativo previamente organizado e aplicado.

Entre as motivações para a reflexão e elaboração de um guia-norteador, se encontram: 1) escassez de materiais que reflitam sobre o processo avaliativo para crianças bilíngues no Brasil; 2) o contato com mães de alunos estrangeiros, sendo essas também estrangeiras (provindas da Venezuela e Síria) e suas impressões e dúvidas sobre o funcionamento do ensino público no Brasil. Em relação ao segundo aspecto, uma inspeção mais próxima da realidade do ensino para crianças bilíngues foi feita após uma entrevista

\footnotetext{
${ }^{1}$ De acordo com Gabriel e Albuquerque (2020, no prelo): "os últimos dados fornecidos pelo CONARE (2018) mostram que no ano de 2018 o Brasil recebeu, aproximadamente, 80 mil solicitações de refúgio, sendo 61.681 apenas de comunidades venezuelanas. Após os solicitantes da Venezuela, se encontram os haitianos, com 7 mil solicitações".

${ }^{2}$ Utilizamos o termo Português para Falantes de Outras Línguas como intercambiável a outros termos, como Português como Língua Adicional por entendermos que a criança bilíngue possui mais de uma língua disponível em seu sistema linguístico para se comunicar e que esta pode ser ativada conforme as funções comunicativas e contextos de uso apresentados. Não se trata de uma língua estrangeira à criança, que não a pertence.
} 


\section{REVISTA DA ABRALIN}

com três mães sobre suas experiências em relação à inclusão dos seus filhos no sistema educacional brasileiro. Entre os diversos relatos sobre seus filhos na escola, um caso específico nos chamou a atenção. Uma das mães, por recomendação da escola, foi orientada a levar seu filho a médicos e psicólogos para descobrir o motivo do comportamento inadequado da criança no ambiente escolar. O diagnóstico para tal comportamento foi o de que a criança não conseguia se expressar, tanto verbal quanto não verbalmente, sobre suas vontades em um ambiente no qual nenhum adulto conhecia sua língua materna. Esse relato nos motivou a criar esse guia voltado aos profissionais do setor educacional (professores e gestores das escolas que atuam diretamente com essa comunidade crianças migrantes), de modo a auxiliá-los com instrumentos avaliativos acessíveis. Os instrumentos têm como objetivo direcionar o olhar dos profissionais para o desenvolvimento linguístico desses alunos, os quais já iniciaram seu processo de educação formal em sua língua materna.

No que diz respeito às caraterísticas do guia-avaliativo, definimos este como um instrumento de avaliação diagnóstica (RETORTA; MAROCHI, 2018), pois tais avaliações permitem evidenciar problemas de aprendizagem, apontar para competências linguístico-culturais que não foram desenvolvidas e, ainda, reforçar conteúdos de aprendizagem que não foram assimilados pelo aluno. O guia também foi baseado no artigo "Assessing Language Development in Bilingual Preschool Children", de McLaughlin et al (1995). O método desenvolvido neste artigo foi de grande relevância para a construção do nosso guia, uma vez que muitas das etapas presentes nas orientações, bem como os materiais no apêndice ${ }^{3}$, foram traduzidos e adaptados a partir do método proposto pelos autores.

Uma vez que o objetivo maior desta discussão é a apresentação e descrição do processo de elaboração de um guia-avaliativo, este artigo se organiza de modo distinto da maioria (os quais são geralmente compostos por uma robusta seção de fundamentação teórica, seguida de metodologia e resultados). Entendemos que os resultados do nosso estudo (a elaboração de um guia-avaliativo para crianças migrantes) também são compostos de fundamentação teórica. Assim, propomos que a seção de resultados, na qual apresentamos o guia-avaliativo em si, também traga as bases teóricas, uma vez que compreendemos o guia-avaliativo como uma ferramenta de exercício da práxis do professor em formação continuada. Para tanto, organizamos o trabalho de forma a apresentar, na seção de Fundo Teórico, as origens do Programa de Extensão de Português para Falantes de Outras Línguas (PFOL) e alguns conceitos importantes sobre avaliação e ensino bilíngue. Após, passamos a explanar sobre a metodologia e resultados (a descrição do guia em si). Por fim, elaboramos algumas considerações finais, seguidas das referências bibliográficas.

\section{Seção de fundo teórico}

\footnotetext{
${ }^{3}$ Os apêndices podem ser consultados através do seguinte endereço: https://drive.google.com/file/d/1RIZdvVZnpjgUXaV5xogX8xgt TKh- V/view? usp=sharing
} 


\section{REVISTA DA ABRALIN}

Esta seção está organizada de modo que, primeiro, descrevemos a origem e o trabalho do Programa de PFOL da Universidade Tecnológica Federal do Paraná, Campus Curitiba (UTFPR-CT), dentro do qual se originou a proposta do guia-avaliativo. Posteriormente, discorremos sobre algumas teorias acerca do conceito de avaliação dentro do ensino bilíngue.

O PFOL da UTFPR-CT iniciou as suas atividades em 2001, em virtude da necessidade da própria instituição em receber estudantes intercambistas (CORDEIRO; BALDIN, 2017). A oferta de cursos e atividades de PFOL é ampliada em 2018 com a entrada de professoras no Departamento Acadêmico de Línguas Estrangeiras Modernas, do Campus Curitiba (DALEM-CT) com interesse nessa área. Em 2012, o ingresso de outras professoras, cujo trabalho tem relação com o PFOL, fortaleceu a área com atividades, tanto sobre formação de professores quanto aulas de português a estrangeiros. Ao mesmo tempo, a cidade de Curitiba e região metropolitana começaram a receber um grande contingente populacional de estrangeiros. Com isso, a procura por cursos de PFOL aumentou proporcionalmente. Assim, o Programa de Extensão em PFOL na UTFPR-CT assumiu uma nova configuração, oferecendo novas turmas, para atender as diferentes necessidades dos alunos estrangeiros e também atividades de formação para licenciandos em Letras, interessados em português para estrangeiros e seu ensino.

Enfatizamos que o Programa de Extensão contempla os eixos estabelecidos por Nogueira (2001) para a Extensão Universitária, a saber: indissociabilidade entre pesquisa, ensino e extensão; questões relacionadas ao impacto social; estabelecimento de uma relação dialógica com a sociedade; e interdisciplinaridade. A participação de alunos dos cursos de Letras Português-Inglês e, mais recentemente, de Letras-Inglês da UTFPR-CT tem sido crescente. Esses acadêmicos integram o Grupo de Pesquisas de Português para Falantes de Outras Línguas (GPPFOL), no qual são feitas leituras, análises e discussões de textos teórico-metodológicos relacionados à formação e à prática docente. Além disso, os alunos dos cursos de Letras-Inglês atuam como monitores nos cursos de PFOL, realizando observações e auxiliando nas aulas que são ministradas pelas professoras regentes. Após orientações e planejamentos, os universitários ministram algumas aulas e auxiliam na preparação de materiais, sempre sob a supervisão dos docentes do GPPFOL.

Ressaltamos, conforme mencionamos anteriormente, a forte relação estabelecida entre o Programa de Extensão PFOL e três disciplinas regulares do Curso de Letras-Inglês da UTFPR: Ensino de PFOL 1 (código CL75E), Ensino de PFOL 2 (código CL76E) e Grupo de Pesquisa de PFOL (CL7AD). Em todas as disciplinas, temos, semestralmente, mais de 60 alunos da graduação de Letras-Inglês atuando diretamente no Programa de Extensão do PFOL. O trabalho desenvolvido nas três disciplinas implica o envolvimento dos acadêmicos em diversas ações, especialmente na produção de materiais didáticos para alunos estrangeiros. Para exemplificar tal dinâmica, chamamos especial atenção para 10 projetos de Recursos Educacionais Abertos (REAs), desenvolvidos na disciplina GPPFOL, em sua edição de 2019/2. Dentre esses, destacamos o que trazemos aqui hoje para discussão: a proposta de um guia-avaliativo para crianças estrangeiras bilíngues na pré-escola como um REA. 


\section{REVISTA DA ABRALIN}

Apesar de a área de PFOL existir de modo mais consistente desde a década de 80 e o mercado editorial dispor de alguns livros didáticos de qualidade, há a carência de materiais didáticos acessíveis ao público atendido pela UTFPR (em sua maioria, migrantes em vulnerabilidade social, adultos e crianças) e que atendam às necessidades específicas do corpo discente acima mencionado (materiais que introduzem os migrantes ao português e suas aplicações no dia a dia: obter um emprego, realizar tarefas diárias do cotidiano, ser reinserido no ambiente escolar regular). Essa dificuldade - ou mesmo impossibilidade - de acesso aos livros didáticos e materiais avaliativos que olhem para um processo de educação bilíngue advém de uma motivação teórico-prática. Um ponto é a inexistência de materiais que contemplem o uso de textos e situações que tenham como orientação a vida no lugar onde se usa a língua-alvo, ou seja, os materiais disponíveis no mercado editorial (em mais alta circulação) não tendem a contemplar a relação entre ensino/aprendizagem em imersão, resultando em materiais demasiado simples e focados basicamente em aspectos estruturais da língua. Outro ponto que merece destaque é o preço dos livros, o que resulta em um valor altíssimo para grande parte dos estrangeiros atendidos. Dado os dois aspectos acima mencionados, temos nos dedicado, enquanto Grupo de Pesquisa, à produção de REAs para o contexto de PFOL, a exemplo do guiaavaliativo que trazemos aqui.

O guia foi baseado no conceito de REA defendido por Leffa (2016), o qual caracteriza tais recursos como materiais "abertos para acesso" e "à mudança", ou seja, materiais acessíveis e que podem ser adaptados de forma gratuita. O nosso guia, enquanto REA, apresenta a possibilidade de ser utilizado e adaptado aos diferentes contextos das escolas brasileiras.

Além da noção de REA, nos pautamos nas necessidades específicas de ensino-aprendizagem de crianças bilíngues e, consequentemente, nas particularidades do processo avaliativo para esse público. Dentre as diversas definições do sujeito bilíngue, atribuímos a palavra bilíngue às crianças que na fase de aquisição linguística desenvolvem, consecutivamente, uma língua adicional ainda na infância, ou seja, estas desenvolvem a língua adicional mesmo que já tenham consolidado algumas estruturas linguísticas na sua língua materna. Assim, é importante estabelecer que essas crianças, ao serem expostas à língua adicional, não se resumem a uma tábula rasa e, sim, a um indivíduo dotado de conhecimento prévio, de diversas funções linguístico-cognitivas na sua língua materna. Portanto, a diferença na avaliação da criança bilíngue está em qualificar tais funções e como essas podem ser melhor exploradas no desenvolvimento linguístico do novo idioma, nesse caso, o Português Brasileiro.

A partir do entendimento de aprendiz bilíngue, apontamos que os processos avaliativos precisam levar em consideração um aspecto chave. Em geral, as crianças migrantes que chegam ao Brasil em idade escolar já passaram por algum sistema educacional em seu país de origem e os conhecimentos adquiridos previamente devem ser levados em consideração na reinserção dos alunos no sistema educacional brasileiro. Nesse sentido, para além da avaliação de produto, a qual é tradicionalmente aplicada no contexto do ensino regular, há a necessidade de se olhar, prioritariamente, para o processo de desenvolvimento linguístico dos aprendizes, para uma avaliação de processo. Pensando em uma complementaridade dos processos de avaliação de produto e processo, Retorta e Marochi (2018) destacam a importância da realização de uma avaliação diagnóstica, pois nela podem ser identificados pontos 


\section{REVISTA DA ABRALIN}

fortes e fracos da criança avaliada em relação à linguagem, bem como são identificados quais elementos precisam ser reforçados após a avaliação. Além desses aspectos, as autoras discutem que, por meio das avaliações diagnósticas, seria possível ainda "verificar" a presença ou ausência de requisitos para novas aprendizagens" (HAYDT, 2002 apud RETORTA; MAROCHI, 2018).

Com proposta similar, esta avaliação permite analisar dentre as competências linguísticas quais o aluno já consolidou, quais está desenvolvendo e quais necessitam desenvolvimento. Contudo, o guia se difere da maioria das avaliações diagnósticas uma vez que estas são aplicadas somente no início do ano letivo. Propomos um processo no qual, ao final da avaliação, sejam elaboradas propostas para suprir as demandas do aluno e, logo em seguida, se reinicie o processo avaliativo novamente. Além disso, de acordo com as autoras, estes testes podem ser elaborados pelo professor e podem ser aplicados para mais de uma turma ou, até mesmo, em uma escala maior. Os resultados, como já mencionado, contribuem para a análise de problemas de aprendizagem podendo indicar competências que não foram desenvolvidas adequadamente ao longo dos anos escolares, bem como apontam conteúdos que não foram assimilados pelo aluno (RETORTA; MAROCHI, 2018).

Procurando não só analisar implicações teóricas, mas também de ordem prática, da inserção de crianças migrantes no sistema educacional brasileiro, foi realizada uma entrevista semi-estruturada com mães, de diferentes nacionalidades (alunas dos cursos de PFOL da UTFPR). Tal entrevista nos alerta para a importância de realização de testes de entrada na escola que operem com diferentes faixas etárias, saberes e competências linguísticas desenvolvidas. Entre os relatos, uma das mães expôs que quando realizou a transferência de sua filha de oito anos de idade para o sistema educacional brasileiro, o critério de adequação da filha aos anos escolares previamente cursados foi estabelecido apenas de acordo com a sua faixa etária e não com o seu nível de conhecimento. A mãe descreveu que a filha frequentava escolas particulares no país de origem e, que quando iniciou seus estudos no Brasil, a filha se destacou como uma das melhores alunas da sala em uma escola pública brasileira, conquistando o primeiro lugar em um concurso de língua portuguesa disputada entre alunos de seu ano e do ano posterior ao dela. Desta forma, a mãe tentou realizar a transferência da filha para o ano escolar seguinte, contudo, a mesma não foi possível. Este relato demonstra a importância de avaliações diagnósticas como um dos instrumentos de adequação dos alunos estrangeiros quando inseridos no sistema educacional brasileiro.

Diante do cenário exposto até o momento, apontamos a importância de entender o desenvolvimento linguístico das crianças migrantes como um processo e a necessidade de serem criados elementos avaliativos adequados. McLaughlin et al (1995) desenvolveu em seu artigo "Assessing Language Development in Bilingual Preschool Children" um método de avaliação do desenvolvimento linguístico de crianças bilíngues na pré-escola. Os autores, além de apresentarem um planejamento sobre o desenvolvimento da linguagem em crianças bilíngues, elaboram um método avaliativo para suprir a demanda de uma avaliação que considere o contexto de crianças bilíngues (espanhol como língua materna e inglês como língua adicional.

Contudo, apesar de existirem propostas como a de McLaughin et al. (1995), essa ainda se encontra intimamente relacionada com um processo de organização de currículo educacional que se foca 


\section{REVISTA DA ABRALIN}

no eixo Norte-Norte, ao invés de Sul-Sul. Neste paradigma, procuramos entender a inserção das crianças migrantes nos valores e estrutura organizacional de povos colonizados, como é o caso da sociedade brasileira. Embora não tenham sido encontradas pesquisas que procurem pensar, mais especificamente, sobre os processos avaliativos para crianças migrantes no Brasil, elencamos aqui duas contribuições que oferecem importantes considerações sobre as relações entre professor e aluno e acerca dos processos de formação continuada com docentes da escola pública.

Russo, Mendes e Borri-Anadon (2020) realizaram uma pesquisa de natureza qualitativa sobre as considerações de docentes (dez professores de ensino Fundamental I de uma escola municipal de Duque de Caxias - Rio de Janeiro), a respeito de processos de migração e/ou refúgio na escola pública. Entre os resultados, as pesquisadoras encontraram que a chegada das crianças migrantes promoveu uma série de reflexões sobre questões com as quais a escola já lidava, como ponderações sobre diferenças e discriminação. Os professores relataram, também, a preocupação com o desenvolvimento das crianças migrantes, uma vez que os processos avaliativos se voltam para o público brasileiro, levando em consideração aspectos linguístico-culturais que as crianças migrantes ainda estão adquirindo. Nesta esteira argumentativa, apontamos a importância de o professor ter um olhar para o PB como língua adicional.

Além do estudo supracitado, apontamos alguns dos resultados de um projeto de extensão criado entre a Universidade Tecnológica Federal do Paraná e membros da comunidade escolar do município de São José dos Pinhais. Embora não tenha sido publicada em forma de pesquisa, descrevemos a proposta elaborada pelos dois órgãos, desenvolvida em 2018-2019. O projeto de extensão se inseriu no contexto da sociedade atual, com um número expressivo de fluxos migratórios e possibilitou a potencialização de atitudes colaborativas, por meio de um pensamento coletivo para a superação dos interesses individuais em busca do bem-estar coletivo. Conforme mencionamos na introdução deste artigo, dados de pesquisas como as realizadas pelo Alto Comissariado das Nações Unidas (ACNUR, 2016) revelam o aumento no número de migrantes refugiados e com visto de auxílio humanitário que têm chegado ao Brasil, devido a guerras civis e desastres naturais. Nesse contexto, políticas de acolhimento (CABETE, 2010; GROSSO, 2010) que procuram olhar para as necessidades desses migrantes, para as convenções sociais que eles precisam dominar em seu novo contexto de vida, bem como para o auxílio na obtenção de bens materiais e simbólicos (NORTON, 2013) se fazem necessárias. Entre os objetivos do projeto de extensão se encontravam a promoção de ações para a formação em serviço do professor que atua na Educação Básica e que possuía ou poderia acolher futuramente alunos advindos dos processos migratórios existentes no atual contexto social brasileiro. Além disso, o projeto procurou contemplar algumas ações com crianças migrantes nas salas de aula de Educação Básica do município de São José dos Pinhais e, eventualmente, suas famílias. Entre os resultados das ações, os envolvidos com o projeto perceberam a necessidade de discussões mais pontuais, com os docentes, entre as diferenças de ensino de português-língua materna e português-língua adicional. Além disso, ao desenvolver rodas de conversas com os alunos e suas famílias, foi observada a importância do entorno na adaptação das crianças e da necessidade de apoio aos docentes em seu processo de formação continuada, para que todos os envolvidos percebam e 


\section{REVISTA DA ABRALIN}

busquem entender os seus papéis diante desse contexto, e que busquem o seu aprimoramento profissional por meio de ações colaborativas.

Ambas as contribuições, de Russo, Mendes e Borri-Anadon (2020) e do projeto de extensão desenvolvido entre a UTFPR-CT e a prefeitura de São José dos Pinhais, mostram a frágil realidade de formação de professores da rede pública e a falta de recursos (materiais e simbólicos) no processo de acolhimento escolar e desenvolvimento de competências linguístico-culturais de crianças migrantes. É nessa esteira que pesquisas como as realizadas dentro do GPPFOL da UTFPR e em outros núcleos de ensino-pesquisa-extensão podem auxiliar na criação de ferramentas teórico-práticas para a avaliação das crianças e acompanhamento dos profissionais da educação básica.

Esperamos que esta seção tenha dado a conhecer o processo de surgimento e elaboração dos REAs dentro do Grupo de Pesquisa em PFOL da UTFPR-CT e os importantes conceitos que constituem o nosso REA. Além disso, procuramos pontuar algumas das contribuições acerca da inserção de crianças migrantes no contexto educacional brasileiro, demonstrando a falta de pesquisas que se proponham a pensar em uma avaliação mais especializada e integradora para este público. Passamos, então, para a descrição de alguns dos procedimentos metodológicos utilizados na elaboração do guia-avaliativo.

\section{Metodologia}

Seguindo algumas das considerações elencadas na introdução deste trabalho, iniciamos a seção de metodologia enfatizando que a proposta discutida por este artigo foca na apresentação e descrição de possíveis etapas para elaboração de uma avaliação, de um guia-avaliativo, e não em uma avaliação que foi anteriormente organizada e aplicada.

O guia-avaliativo foi desenvolvido para a avaliação do amadurecimento linguístico de crianças de 4 a 6 anos de idade e esta avaliação foi construída pela forma como essas crianças utilizam a linguagem em diversas situações, considerando principalmente os fatores gramaticais, de pronúncia e de vocabulário. É válido destacar ainda que esta avaliação é focada no processo de desenvolvimento da língua materna e também da língua adicional, o que significa que este instrumento não considera apenas fatores quantitativos como a atribuição de notas aos alunos e sim aspectos majoritariamente qualitativos, levando em consideração o desenvolvimento linguístico enquanto processo e não apenas produto.

Destacamos ainda que nos referimos a esse material como guia-avaliativo pelo fato de que sua proposta é modificável e não pretende ser finita, i.e., ressaltamos que é possível e importante a realização de adaptações no processo avaliativo de acordo com o contexto e que não há um número fixo de avaliações a serem administradas. 


\section{REVISTA DA ABRALIN}

A proposta de avaliação aqui disposta é composta por cinco etapas, as quais advogamos serem necessárias para uma avaliação holística das habilidades linguísticas desenvolvidas pela criança, a saber:

I. A primeira etapa diz respeito a aspectos da organização de todo o processo avaliativo. Nela, a equipe pedagógica e o avaliador estruturam como a avaliação será feita.

II. Na segunda etapa, há a coleta de informações, assim, o avaliador irá observar a criança e tomar notas sobre como a mesma utiliza a linguagem durante um período de tempo.

III. Após o período de observações, seguimos com a terceira etapa, na qual todas as anotações serão anexadas ao portfólio da criança e este, por conter os dados da criança, será essencial para a criação do parecer necessário nas próximas etapas.

IV. Na quarta etapa, a equipe pedagógica, o avaliador e os pais e/ou responsáveis se reúnem para compartilhar as informações obtidas até o momento.

V. Na quinta e última etapa, a equipe pedagógica e o avaliador elaboram uma estratégia educacional para fortalecer o desenvolvimento linguístico da criança.

Nenhuma das etapas possui um período de tempo determinado para a sua execução, porém, estima-se em torno de seis meses de coleta de informações no portfólio da criança para que, então, inicie-se a elaboração da primeira estratégia educacional. Essas estratégias visam a elaboração de um plano com atividades adequadas que auxiliem o desenvolvimento da criança. Ao finalizar cada uma das etapas, o avaliador deve recomeçar o processo de avaliação levando em consideração a estratégia adotada.

Conferimos a denominação de avaliador à pessoa que irá realizar as etapas. Como as etapas envolvem a observação do aluno em contexto de sala de aula, consideramos que o avaliador pode ser o professor regente, o auxiliar da turma, ou qualquer outro profissional da educação, como pedagogos e psicólogos, que possam desempenhar tal função. As orientações presentes nas etapas deste guia são direcionadas aos avaliadores, por isso, a linguagem adotada durante as etapas foi adequada a esse público (nos dirigimos, portanto, na seção 4 ao avaliador como "você"). Ressaltamos ainda que, por essa avaliação decorrer de um processo avaliativo, o avaliador deve repassar o portfólio sobre o desenvolvimento do seu aluno caso ocorra a mudança de avaliador. Essa troca de informações entre avaliadores deve ocorrer de forma que outro avaliador possa dar continuidade a essa avaliação nos meses ou anos subsequentes.

Esse guia, embora tenha como público-alvo os professores (os quais chamamos de avaliadores), ainda abrange a participação e colaboração de pais e responsáveis durante o processo. Essa 


\section{REVISTA DA ABRALIN}

colaboração poderá ocorrer por meio de reuniões ou conversas informais e servirá aos avaliadores como uma ferramenta para compreender melhor o desenvolvimento dos alunos.

\section{Resultados}

Conforme mencionamos anteriormente, a seção de resultados possui um formato bastante robusto, pois traz o guia-avaliativo como um REA a ser aplicado no contexto de ensino regular de crianças migrantes bilíngues no Brasil. Cada subseção descreve e aponta procedimentos avaliativos importantes para o avaliador. Chamamos a atenção para o fato de que, como o guia foi pensado em ser lido diretamente pelo avaliador (ou comissão avaliadora responsável pelo processo de ensino-aprendizagem da criança migrante na escola), passamos a usar uma voz discursiva mais próxima, chamandoo de "você".

3.1 Primeira etapa: planejando a avaliação

Começaremos pela primeira etapa, na qual ocorre o planejamento de todo o processo da avaliação. Aqui, você irá se reunir com a equipe pedagógica e, juntos, irão organizar de que maneira a avaliação acontecerá.

\section{Por onde começar?}

Ressaltamos que ao avaliar os alunos estrangeiros deve-se levar em consideração as experiências que esses têm em sua língua materna e adicional. $\mathrm{O}$ aluno estrangeiro possui um conhecimento prévio derivado da sua cultura e vivência linguística, mas tais aspectos muitas vezes são desconsiderados unicamente porque o aluno não possui o código linguístico da língua-alvo (neste caso, o PB). Contudo, não dispor do domínio da língua adicional não significa que o aluno estrangeiro não possa ser avaliado, mas sim que esta avaliação deve seguir um formato que priorize o desenvolvimento contínuo da língua adicional em relação a sua língua materna.

Um dos primeiros passos ao avaliar crianças é querer obter resultados condensados, ou seja, um produto que é resultado de diversas atividades reunidas. Como forma de alerta, para que se evite o acúmulo de atividades que buscam um produto relativamente homogêneo de todos os alunos da turma, este guia contém algumas recomendações de como e quando essa avaliação pode ser realizada. Por meio da Figura 1, selecionamos os principais pontos que devem ser definidos na primeira etapa do processo avaliativo. 


\section{REVISTA DA ABRALIN}

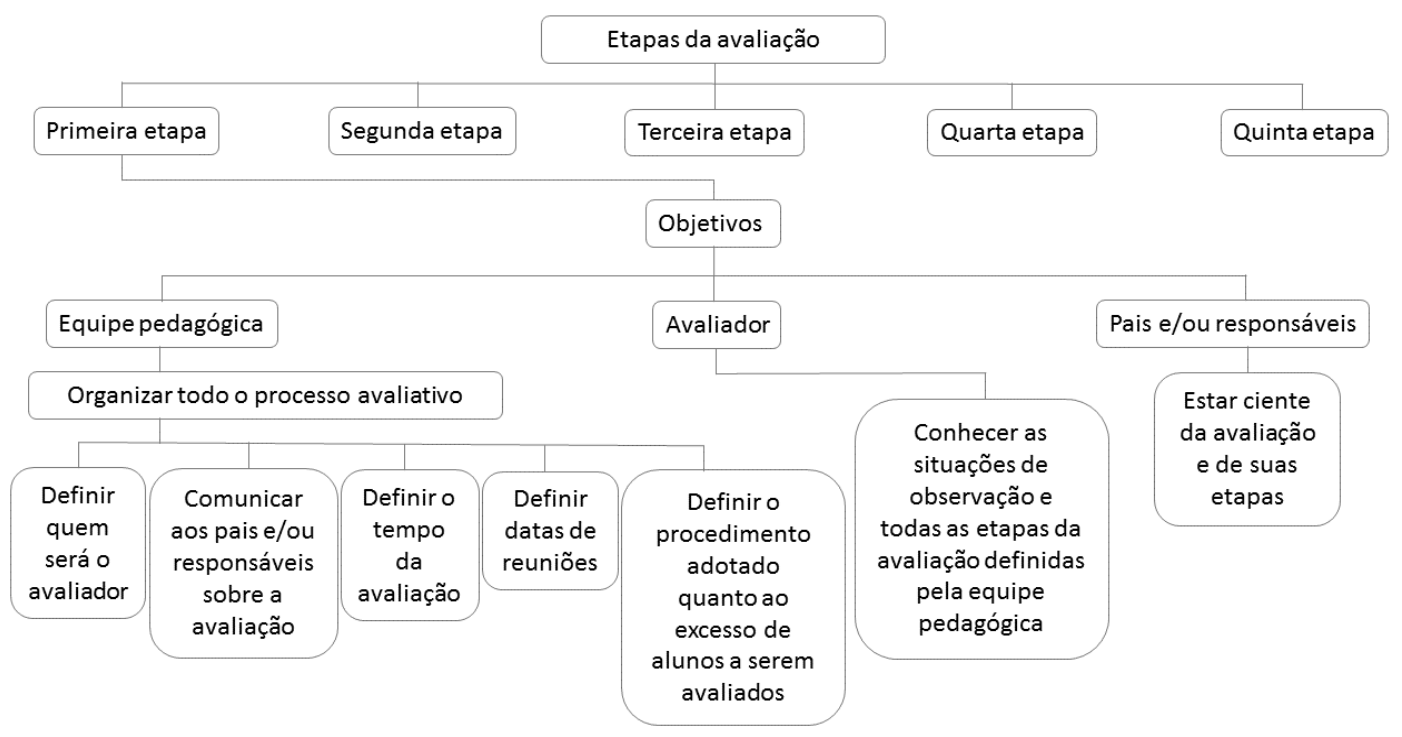

FIGURA 1- Primeira etapa

- $\quad$ Equipe pedagógica

Para o avaliador existem limitações quanto a alguns aspectos administrativos sobre os alunos e sobre a escola. Por isso, nesta avaliação se faz necessário a incorporação da equipe pedagógica no processo como um todo. A principal função da equipe pedagógica é não só a de organizar o processo avaliativo e auxiliá-lo como avaliador, bem como a de auxiliar os pais e/ou responsáveis em relação a possíveis dúvidas quanto ao processo. Então, ao final dessa primeira etapa, a equipe pedagógica deve ter o conhecimento de todas as etapas seguintes e também sobre como estas etapas serão aplicadas e/ou adequadas ao contexto da escola.

A equipe pedagógica é responsável por comunicar pais e/ou responsáveis sobre a avaliação e sanar eventuais dúvidas destes. Esta também definirá datas para as reuniões tanto com os avaliadores, quanto com os pais e/ou responsáveis, uma vez que essas reuniões são imprescindíveis nas etapas quatro e cinco. Definindo as datas dessas reuniões, a equipe pedagógica logo determinará o tempo de avaliação para cada etapa. Em relação a este último, recomendamos que sejam seis meses de observação (ou um tempo entre um ciclo de atividades e outro) e recolhimento do material para o portfólio antes da quarta etapa.

Existem mais de dois alunos para serem avaliados em uma turma, o que fazer?

Em casos excepcionais de turmas com grande número de alunos estrangeiros para serem avaliados, a recomendação é que seja definido um formato de avaliação que atenda todas as crianças e 


\section{REVISTA DA ABRALIN}

não sobrecarregue o avaliador. Para esses casos, nossa sugestão é de que sejam selecionadas de duas a três crianças na semana para a observação, isso possibilitará a avaliação de todas essas crianças em diversos contextos ao longo do ano.

\section{- Avaliador}

Uma vez que este guia possui uma orientação que procura ser holística, você deve sempre se comunicar com a equipe pedagógica sobre as direções tomadas para a avaliação. Em vista disso, os avaliadores precisam estar cientes de sua função, das etapas do processo e de como analisar cada aluno nos casos onde existe mais de um aluno a ser avaliado.

Nesta etapa, você irá se preparar para a etapa seguinte da avaliação, na qual são feitas algumas observações sobre como a criança utiliza a língua. Portanto, é necessário que sejam observados o uso da linguagem, não apenas da língua materna, mas também da língua adicional do aluno em diversos contextos. Esses contextos de observação dizem respeito a situações vivenciadas pelas crianças na escola, portanto você poderá analisar o uso da linguagem da criança para:

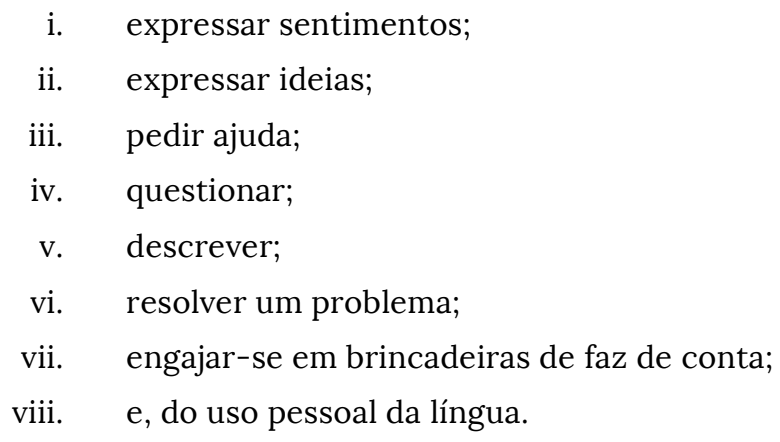

É importante que você, como avaliador, tenha em mente essas situações de comunicação para percebê-las quando a criança propicia esses momentos de uso da linguagem. Para isso, logo abaixo, o avaliador pode utilizar o material de auxílio sobre as situações de observações que contém sugestões sobre quando estas podem ocorrer (ver Tabela 1).

Vale lembrar que essas situações na qual a criança usa a linguagem podem acontecer a qualquer momento, sendo assim, é preciso estar sempre atento. 


\section{REVISTA DA ABRALIN}

\begin{tabular}{|c|c|}
\hline \multicolumn{2}{|c|}{ Situações para a observação das crianças } \\
\hline $\begin{array}{ll}\text { 1-Expressar sentimentos } \\
\checkmark & \text { Expressar raiva } \\
\checkmark & \text { Expressar alegria } \\
\checkmark & \text { Expressar arrependimento }\end{array}$ & $\begin{aligned} & \text { 2-Expressar ideias } \\
& \checkmark \text { Sobre como fazer tarefas } \\
& \checkmark \text { Sobre a natureza } \\
& \checkmark \text { Sobre a utilização de objetos, brinquedos e } \\
& \text { ferramentas }\end{aligned}$ \\
\hline $\begin{array}{l}\text { 3-Para pedir ajuda } \\
\checkmark \text { Quando machucado } \\
\checkmark \text { Quando tentando resolver um problema } \\
\checkmark \text { Quando trabalhando em um projeto escolar }\end{array}$ & $\begin{array}{l}\text { 4- Questionar } \\
\qquad \text { o nome das coisas } \\
\checkmark \text { como algo funciona } \\
\checkmark \text { os porquês das coisas }\end{array}$ \\
\hline $\begin{array}{ll}\text { 5-Descrever } \\
\checkmark \text { Quando relata uma história autêntica } \\
\checkmark \text { Quando relata experiências passadas } \\
\checkmark \text { Quando reconta algo já mencionado } \\
\checkmark \text { Quando descreve uma imagem ou foto }\end{array}$ & $\begin{array}{l}\text { 6-Resolver um problema } \\
\checkmark \quad \text { com outra criança } \\
\checkmark \text { que ocorreu durante uma tarefa } \\
\checkmark \quad \text { que ocorreu durante uma brincadeira }\end{array}$ \\
\hline $\begin{array}{l}\text { 7-Engajar-se em brincadeiras de faz de conta } \\
\checkmark \text { Quando reveza papéis na brincadeira } \\
\checkmark \text { Quando mantém o papel na brincadeira }\end{array}$ & $\begin{array}{ll}\text { 8-Uso pessoal da língua } \\
\checkmark & \text { Para rimas } \\
\checkmark & \text { Para cantar } \\
\checkmark & \text { Para trava-línguas }\end{array}$ \\
\hline
\end{tabular}

\section{TABELA 1 - Situações para a observação das crianças}

Fonte: adaptado de McLaughlin et al (1995).

Essas são algumas das sugestões em que podem ser observadas o uso da linguagem. Para tanto, o avaliador, ao longo da primeira etapa, deve estar familiarizado com essas situações.

\section{- $\quad$ Pais e responsáveis}

Ressaltamos que os pais e/ou responsáveis também devem estar cientes de como ocorre esta avaliação pois a família desempenha papel importante neste processo. Sempre é válido questionar familiares sobre características pessoais da criança avaliada (tímida, extrovertida, curiosa) e como ela se comunica em casa durante o começo ou ao final da aula. Essas pequenas considerações dos pais podem servir como base para mais a frente, a criação de uma estratégia educacional. 


\section{REVISTA DA ABRALIN}

Como dito anteriormente, a segunda etapa do processo é a coleta de informações sobre o desenvolvimento linguístico dos alunos na prática. Ao final dessa primeira etapa, todos os envolvidos, equipe pedagógica, avaliador e pais e/ou responsáveis, devem concluí-la com todos os aspectos devidamente estabelecidos.

\section{Perguntas a serem respondidas ao final da etapa:}

- Você reconhece o seu papel dentro desta etapa?

- Você sabe quem é o avaliador e qual o tempo de avaliação?

- Você tem conhecimento e está de acordo com as datas definidas para as reuniões?

\subsection{Segunda etapa: Coleta de informações}

Após as definições estabelecidas na etapa anterior, iniciamos agora a segunda etapa, a qual consiste na coleta de informações sobre o desenvolvimento linguístico da criança avaliada.

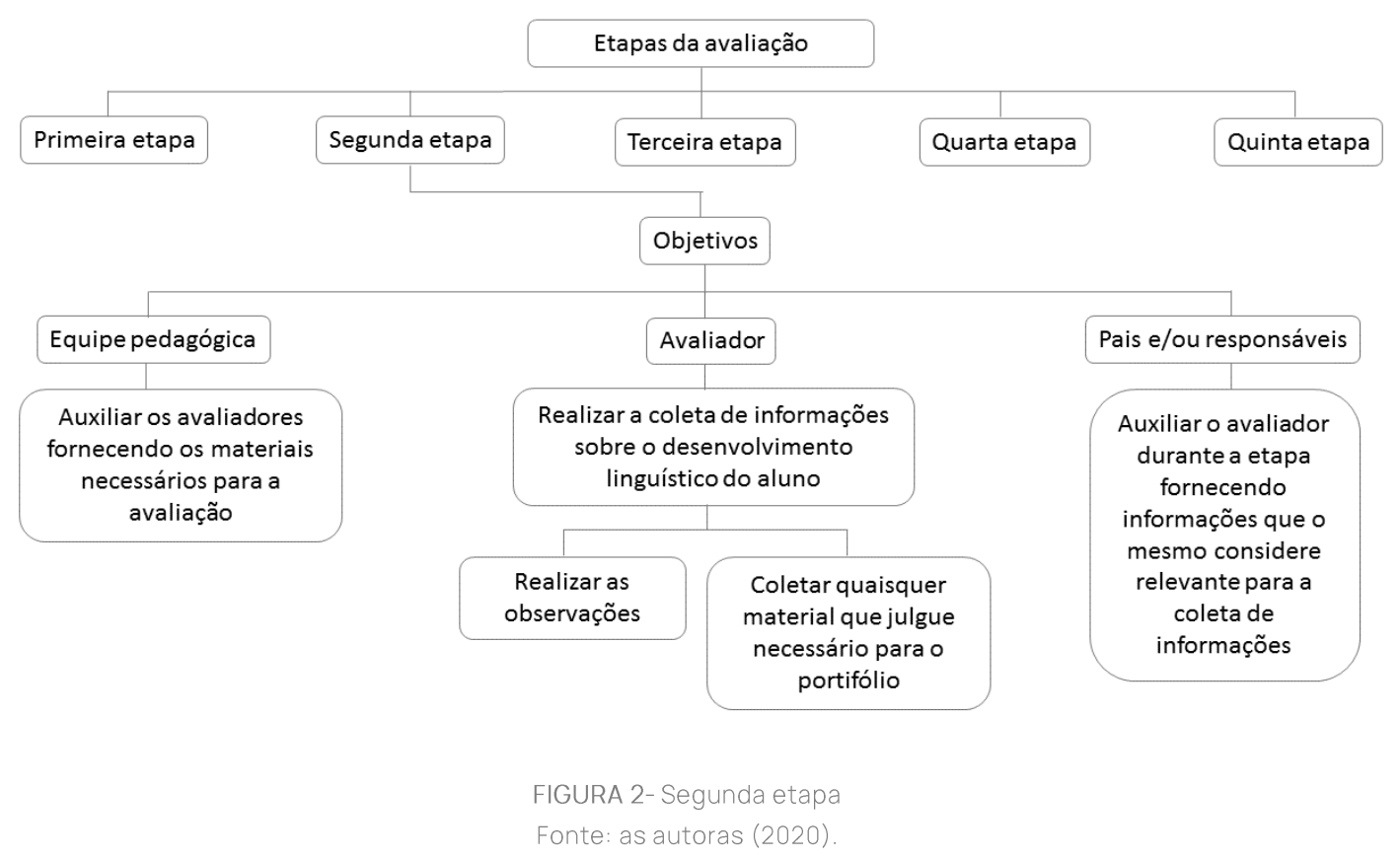

Aqui, realizamos a coleta de informações linguísticas do aluno e, para isso, você deve realizar as observações baseando-se nas situações de comunicação apresentadas na Tabela 1. Uma vez que você perceba alguma situação comunicativa sendo anunciada pelo aluno avaliado é preciso anotá-la 


\section{REVISTA DA ABRALIN}

explicitando como esta situação comunicativa ocorreu. As situações apresentadas neste guia são algumas opções, porém ao longo da rotina de sala de aula podem surgir outras que não foram previstas neste guia.

Como forma de não confundir ou esquecer essas anotações, sugerimos que essas sejam feitas a partir de notas no celular ou, até mesmo, de post-its. A princípio, essas anotações não precisam ser extensas, mas advertimos que o uso de palavras-chave pode dificultar a leitura e, assim, o trabalho seria dobrado ao repassar essas anotações para um modelo formal.

Em um segundo momento, você irá transferir essas anotações referentes ao aluno para um modelo formal, o qual será usado como material para as próximas etapas. Na Figura 3, expomos um exemplo do modelo formal das anotações:

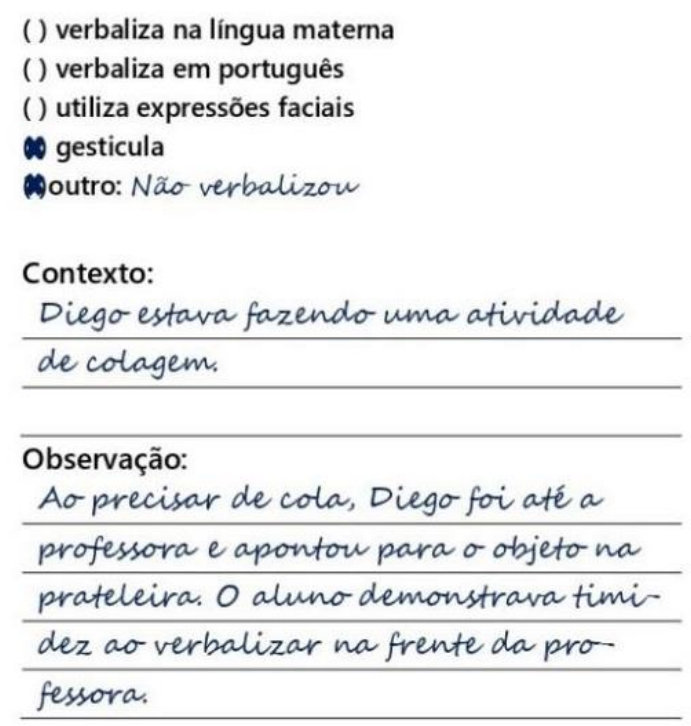

Neste modelo, se faz necessário que seja identificado o modo como a criança realiza a comunicação e, para isso, seguem algumas exemplificações: verbaliza na língua materna, verbaliza em português, gesticula, assente com a cabeça, utiliza linguagem corporal (como expressões faciais), entre outros. A seguir, você irá preencher o contexto no qual o aluno realizou a comunicação. Este se encontra relacionado com as situações que o aluno está envolvido quando utiliza a língua, como por exemplo, brincando com os colegas, fazendo uma atividade, pedindo ajuda, entre outros. Por fim, é feita a escrita de suas considerações sobre a observação em si.

Pensando em contribuir com a avaliação, disponibilizamos um modelo de coleta dessas informações ao final do guia (ver Apêndice A), que deve ser preenchido com as anotações em relação 


\section{REVISTA DA ABRALIN}

tanto a língua materna da criança, quanto do português. Você pode repassar suas anotações para o modelo formal ao final da aula, da semana ou, ao final da etapa, como preferir.

Mas, para que esse modelo formal das observações serve?

Adiantamos que as anotações no modelo formal são imprescindíveis na avaliação pois é um material que será usado nas outras etapas. Este modelo será apresentado à equipe pedagógica e aos pais e/ou responsáveis como uma comprovação de que a segunda etapa da avaliação foi realizada. Ao final deste guia, também veremos que este material poderá ser usado por outros profissionais e avaliadores para averiguar o desenvolvimento do aluno e dar continuidade ao processo avaliativo.

A coleta de informações abrange somente o material coletado das observações?

Não, veremos adiante que anexado às observações é facultada a opção de serem acrescentados desenhos, atividades e até mesmo vídeos que a criança produziu durante o período de observações. Qualquer material que demonstre o desenvolvimento linguístico do aluno é válido.

Meu aluno não fala, o que eu faço?

Um dos problemas dessa etapa, apontado por McLaughlin et al (1995), é ignorar as crianças que permanecem quietas na maioria dos momentos de avaliação. Todavia, o avaliador deve considerar o fato de que algumas crianças podem não verbalizar durante o período de observações, apresentando o que os autores denominam de "período de não verbalização". Se o aluno se encontra em um período de não verbalização é difícil que você consiga realizar a coleta das informações. Nesses casos, onde há limitações acerca das situações em que o aluno utiliza a língua, é necessário que você, como avaliador, propicie situações nas quais o aluno se sinta incentivado a usar a linguagem, como por exemplo, promover com que a criança faça relatos, conte histórias, participe de jogos, entre outros. Não obstante, a família pode ser outra fonte de informação nesses casos e conhecer aspectos pessoais de como a criança se comunica em casa pode ajudar na forma que o avaliador realizará as primeiras estratégias educacionais.

Os outros integrantes participam desta fase?

Sim, a equipe pedagógica e pais e/ou responsáveis são incumbidos na tarefa de auxiliar você da melhor maneira possível. À equipe pedagógica cabe prover os materiais necessários para a avaliação, como itens de papelaria, livros de história infantil, entre outros. Por outro lado, os pais e/ou responsáveis podem fornecer retornos e explicações sobre o desenvolvimento linguístico de seus filhos em casa, durante a entrada e saída da escola. 


\section{REVISTA DA ABRALIN}

A conclusão desta etapa é dada somente após o tempo pré-determinado para a coleta de informações. Na próxima etapa, iremos reunir e analisar todos estes dados coletados.

\section{Perguntas a serem respondidas ao final da etapa:}

- As observações foram realizadas? Até mesmo nos casos dos alunos que são quietos?

- As observações foram redigidas para o modelo formal?

- Os prazos de observação estipulados foram cumpridos?

\subsection{Terceira etapa: Portfólio}

Após a coleta de informações, ou seja, da escrita das observações em um modelo formal, agora criamos um portfólio individual de cada aluno reunindo todos os seus materiais produzidos durante o período de coleta de informações.

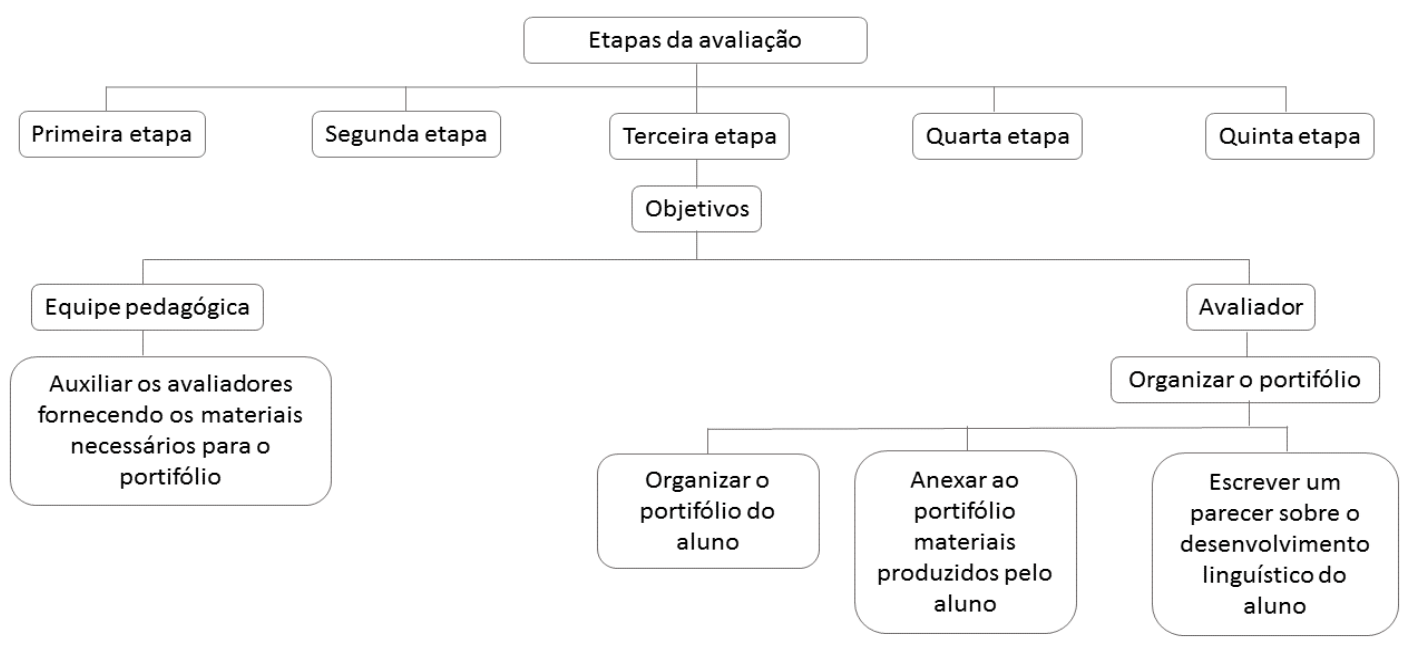

Figura 4- Terceira etapa

Fonte: as autoras (2020).

Mas, o que são esses materiais produzidos pelos alunos?

Esses materiais abrangem as anotações das situações de comunicação (observações) e, também, os materiais que o próprio aluno produziu em sala, como: desenhos dos quais ele descreveu em sala, 


\section{REVISTA DA ABRALIN}

vídeos sobre alguma apresentação musical, e até mesmo, os relatos que os pais e/ou responsáveis forneceram na etapa anterior. Esses materiais devem ser anexados a uma pasta do aluno.

Criei o portfólio, e agora?

Com todos os dados, anotações e materiais reunidos no portfólio, você irá analisá-lo e escrever um pequeno parecer que resume o desenvolvimento linguístico da criança avaliada. Mas, como escrever esse parecer? Disponibilizamos algumas instruções para ajudá-lo ao final do guia (ver Apêndice B), assim, com base nos itens sugeridos, você poderá analisar quais são os pontos fortes e fracos do aluno em relação à língua e habilidades com a língua (que ações a criança desempenha). Ao analisar tais pontos, você deve direcionar especial atenção aos detalhes das produções linguísticas das crianças. Muitas vezes, elas podem não produzir uma frase completa e sem inadequações, mas isso não significa que elas não estejam se comunicando. Nesse sentido, as semi-produções e produções híbridas também são incluídas nesta avaliação.

Após a análise, você irá escrever um parecer que apresenta todo o processo de desenvolvimento desse aluno durante o período avaliativo. Aqui, note um pequeno exemplo que analisa e resume alguns dos aspectos linguísticos apresentados pela criança:

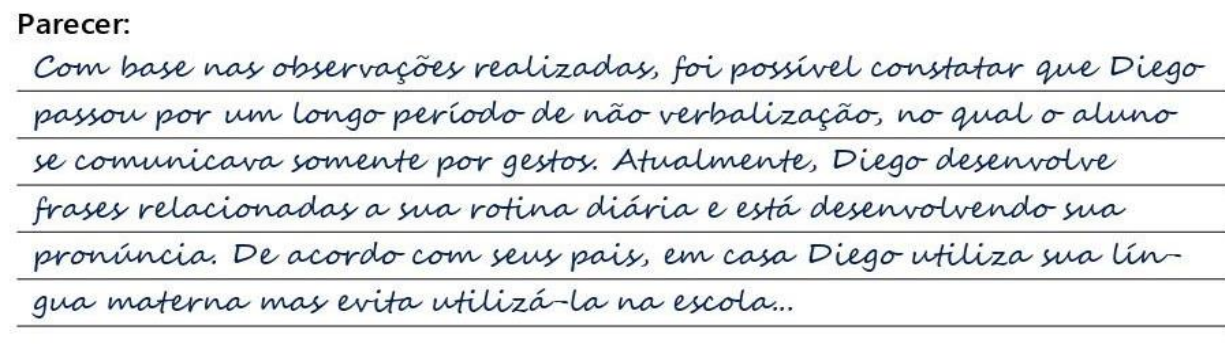

No presente guia, existe um modelo para que você produza este pequeno parecer e o anexe ao portfólio (ver Apêndice C). A seguir, na penúltima etapa, é o momento em que todos os dados do aluno são apresentados à equipe pedagógica e aos pais e/ou responsáveis. 


\section{REVISTA DA ABRALIN}

Perguntas a serem respondidas ao final da etapa:

- Os materiais coletados dos alunos estão no portfólio?

- Ocorreu a análise do material coletado?

- $\quad$ Ocorreu a escrita do parecer?

\subsection{Quarta etapa: Encontro pedagógico}

A penúltima etapa é o momento em que você se reúne com a equipe pedagógica e com os pais e/ou responsáveis para transmitir tudo o que ocorreu durante o processo avaliativo até o momento.

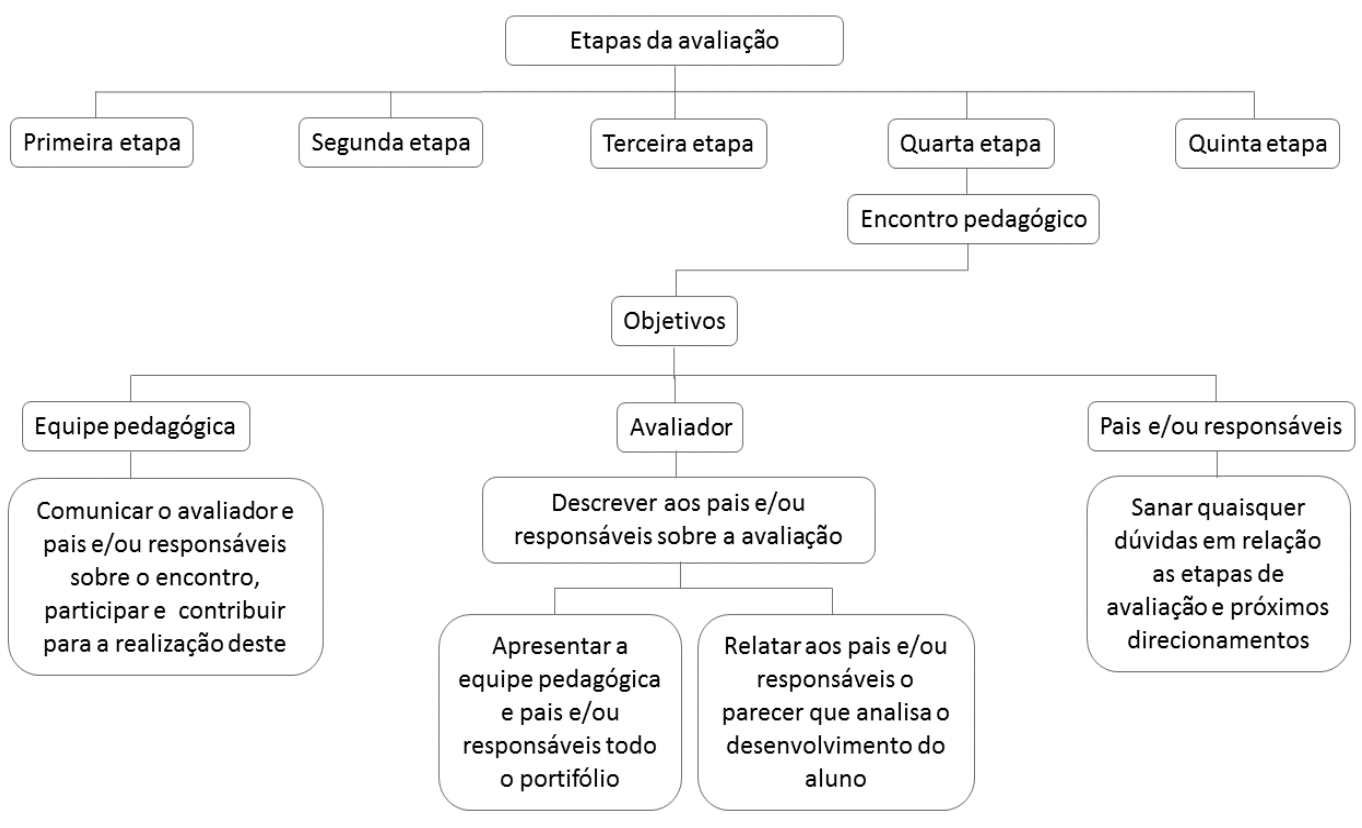

FIGURA 6 - Quarta etapa

Fonte: as autoras (2020).

Quem é responsável por entrar em contato com os pais e/ou responsáveis?

À equipe pedagógica, pois esta possui acesso aos dados pessoais dos responsáveis pelos alunos. É importante ressaltar que a equipe pedagógica participa do encontro, uma vez que é o momento em que todos os integrantes ficam cientes de tudo o que já foi desenvolvido na avaliação.

Como apresentar aos pais e/ou responsáveis tudo o que foi desenvolvido? 


\section{REVISTA DA ABRALIN}

Primeiramente, sugerimos que o espaço seja acolhedor, para que os convidados se sintam confortáveis em compartilhar suas opiniões. Para que isso ocorra, existem alguns procedimentos, como: a disposição de cadeiras em círculo como se fosse uma roda de conversa; fazer uma breve apresentação sobre você e as demais pessoas no encontro; pedir para que os pais e/ou responsáveis também se apresentem. Salientamos que ao relatar os dados dos alunos, as informações sejam apresentadas com o uso de figuras, como por exemplo, a utilização de informações não verbais a partir de emojis. Dado que os pais das crianças bilíngues também são estrangeiros e podem possuir alguma dificuldade de compreensão do PB, a exposição visual pode se mostrar mais inteligível.

A seguir, descreva como sucedeu a coleta de informações, mostre o portfólio e sua análise quanto às necessidades do aluno e, por fim, o parecer.

O parecer é um documento que permanece na escola para uso pedagógico da equipe e para o histórico da criança. Portanto, é necessário que uma versão seja disponibilizada para os pais e/ou responsáveis de forma mais visual, visando também facilitar seu entendimento por meio de imagens e figuras.

Aproveite o momento e converse durante a apresentação sobre o que o aluno faz em casa, contrastando com o que o aluno faz na escola e tire quaisquer dúvidas que os pais e/ou responsáveis tenham sobre as etapas anteriores e as próximas.

A realização desta etapa é de extrema importância pois, a experiência escolar e familiar relatadas nesse encontro darão origem a elaboração de uma estratégia educacional, a qual será descrita a seguir na última etapa.

\section{Perguntas a serem respondidas ao final da etapa:}

- Os pais e/ou responsáveis compareceram ao encontro?

- O portfólio e o parecer foram apresentados?

- Todas as dúvidas foram sanadas?

\subsection{Quinta etapa: Elaborando uma estratégia educacional}

Na última etapa são considerados todos os dados colhidos anteriormente para que seja desenvolvida uma estratégia educacional com o intuito de atender as demandas do aluno. Para alcançar este objetivo, você utilizará as informações do parecer elaborado anteriormente e irá propor alternativas para o desenvolvimento da criança avaliada. 


\section{REVISTA DA ABRALIN}

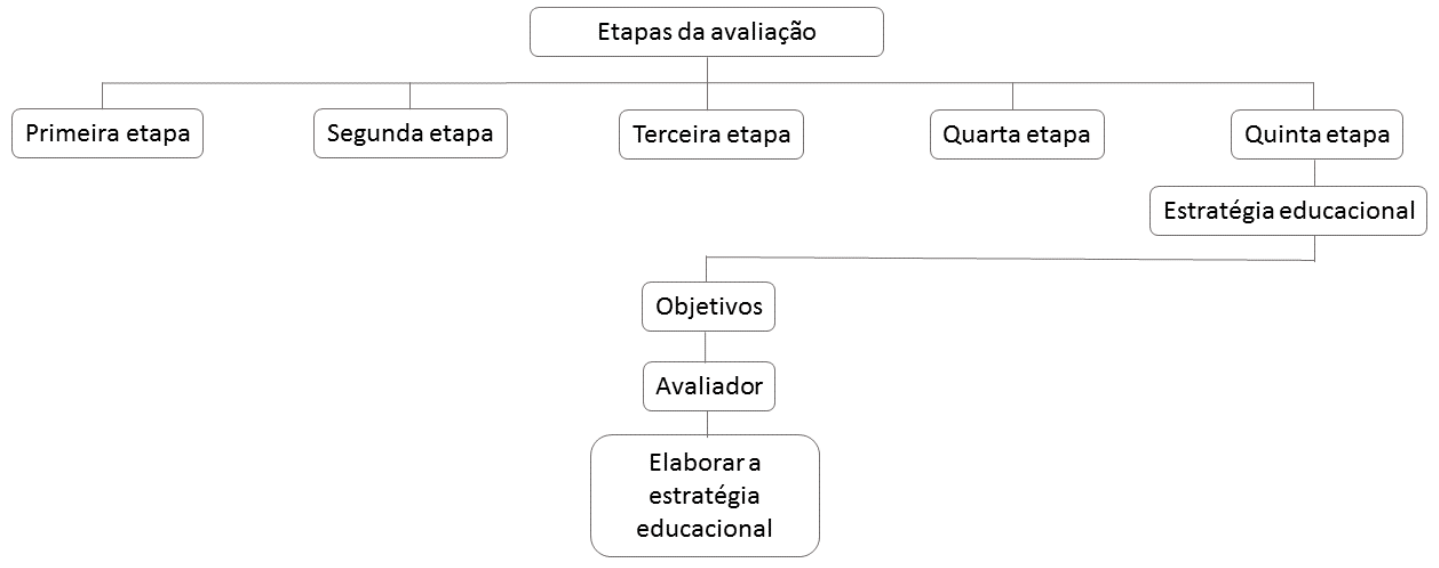

FIGURA 7- Quinta etapa

Fonte: as autoras (2020)

A proposta principal da estratégia educacional é a de proporcionar ao aluno atividades que estimulem o desenvolvimento de suas habilidades linguísticas. As estratégias mais comuns ao público infantil bilíngue são a adoção de cartões de vocabulário (flashcards), músicas, vídeos, uma rotina em sala de aula, jogos, contações de história, dentre outros.

Como criar uma estratégia educacional?

Com base na análise do aluno, é fácil identificar seus pontos fortes e fracos em relação à língua, portanto, por meio das observações, é viável a criação de um plano para que os pontos fracos sejam desenvolvidos e os fortes sejam potencializados. Aqui, você deve considerar também os relatos dos pais e/ou responsáveis que foram apresentados durante o encontro, lembrando que o plano também pode considerar atividades que podem ser desenvolvidas fora do ambiente escolar contanto que os pais e/ou responsáveis estejam cientes, dispostos a participar e a promover tais atividades.

Em seguida, o plano será escrito e anexado junto do parecer ao portfólio do aluno. Na Figura 8, você encontra um exemplo de estratégia educacional, o qual se encontra mais detalhado no Apêndice C.

\section{Estratégia educacional:}

$O$ avaliador decidiu utilizar una rotina diária para estimular $\sigma$ português de Diego. A criação de rotinas diárias são ideais para a aquisição de vocabulário devido a repetição de frases... 


\section{REVISTA DA ABRALIN}

Esta estratégia elaborada deve ser implementada na rotina escolar do aluno, visando otimizar tais pontos. É importante lembrar que estas serão aplicadas logo após serem desenvolvidas, por isso, mesmo que esta seja a última etapa do guia-avaliativo, não significa necessariamente sua finalização, como explicaremos a seguir.

\section{Perguntas a serem respondidas ao final da etapa:}

- Atividades para o desenvolvimento do aluno foram propostas?

- A estratégia educacional foi escrita?

- Os pais e/ou responsáveis podem auxiliar o desenvolvimento do aluno de alguma forma?

\subsection{O fim e recomeço da avaliação}

A avaliação não se encerra ao final da última etapa, pois ela se dá de forma contínua, cíclica. Ao final da quinta etapa, retorna-se à primeira e recomeça-se a mesma avaliação, com o adicional de uma estratégia pedagógica.

Mas, como dar continuidade a esta avaliação?

Ao recomeçar a avaliação, o avaliador considera todos os aspectos já avaliados, analisados e a estratégia utilizada. O avaliador reinicia o processo levando em consideração a proposta de estratégia educacional definida, para que possa averiguar o quanto o aluno aprimorou sua língua adicional desde a implementação. Desta forma, a avaliação irá suceder de forma contínua.

Como repassar uma avaliação já concluída para outro avaliador dar a continuidade?

Neste caso, é importante que os dois avaliadores se reúnam para discutir os aspectos prévios da avaliação do aluno. $\mathrm{O}$ avaliador sucessor deverá saber quais foram as estratégias propostas para dar continuidade a avaliação, bem como, quais eram as dificuldades do aluno anteriormente para, somente assim, poder avaliar no futuro o desenvolvimento (ou não) linguístico do aluno.

Ao final, quem fica com o portfólio?

Com a equipe pedagógica. O portfólio é um documento essencial nessa avaliação pois contém os dados, o parecer e a estratégia educacional. Consideramos o portfólio como uma biblioteca de informações sobre o aluno e um documento com o qual os avaliadores podem e devem sempre 


\section{REVISTA DA ABRALIN}

consultar. Portanto, ao longo das avaliações, o portfólio não é descartado. Pelo contrário, ele é visto com um produto a ser continuado.

Qual é a diferença entre essa avaliação e as demais?

Uma das diferenças é que esta avaliação é dada por um processo que visa resultados qualitativos, enquanto que a maioria das avaliações direcionadas a esse público pretende atribuir apenas notas quantitativas aos seus alunos. A segunda diferença é a de que esta avaliação é contínua, podendo ocorrer durante os três anos definidos ao público-alvo (dos 4 aos 6 anos de idade). Isso significa que durante este período podem ocorrer mudanças exteriores ao aluno, como a mudança de turma e de avaliador. Este aspecto da continuidade da avaliação é exclusivo deste processo alternativo, o que dificilmente pode ocorrer durante uma avaliação que segue o processo padrão, como por exemplo, durante uma prova avaliativa.

\section{Considerações Finais}

Aprender a ensinar é um processo de socialização, isto é, um processo pelo qual as pessoas adquirem seletivamente valores, atitudes, interesses, destrezas e conhecimentos - a cultura comum aos grupos aos quais pertencem ou aos grupos que pretendem pertencer. Esse processo ocorre em vários níveis e é fruto de diversas influências, persistindo ao longo da vida.

O processo para se tornar professor deve ser construído durante a longa trajetória da história profissional de cada um. É um processo lento, contínuo, permanente e deve ter como critério principal o compromisso individual e institucional para esse fim. A definição de desenvolvimento profissional deve ultrapassar a concepção de domínio de técnicas e conhecimentos necessários para a atividade de ensino, conforme os estudos de Russo, Mendes e Borri-Anadon (2020) e o projeto de Extensão entre a UTFPR e a Secretaria de Educação de São José dos Pinhais apontam.

Sem dúvida, a aprendizagem para a docência é um processo complexo. Ela depende da compreensão e articulação entre vários conhecimentos, destacando o específico (área de conhecimento de formação e atuação) e o pedagógico (como relacionar-se, como ensinar, como enfrentar a diversidade e as situações complexas, entre outros fatores). Ressaltamos que, a partir da formação inicial para a docência, o professor permanece se desenvolvendo e aprendendo sua prática profissional no contexto institucional e essa aprendizagem requer entendimento do seu desdobramento. Nesse sentido, entendemos a proposta de elaboração do guia-avaliativo como um convite para que o professor seja pesquisador da sua própria prática e para que o guia, enquanto instrumento educativo, possa fortalecer e indicar um caminho possível e coerente para o desenvolvimento das aulas de português.

Lembramos que se trata de uma proposta de um guia-avaliativo para crianças migrantes que ingressam no ensino educacional brasileiro ainda não testada. Sendo assim, devem ser consideradas pela equipe pedagógica, durante o planejamento, todas as situações referentes à estrutura da escola, 


\section{REVISTA DA ABRALIN}

à capacitação de professores, de alunos a serem avaliados e pais e/ou responsáveis. As etapas, apesar de apresentarem uma sequência, são passíveis de alterações de acordo com o contexto escolar.

A partir de uma primeira aplicação deste guia, o mesmo indicaria modificações e adaptações aos diferentes contextos e isso contribuiria para o aperfeiçoamento da avaliação. Sendo assim, temos como proposta de aprofundamento para futuras pesquisas a aplicação do guia em diferentes turmas e escolas brasileiras. Contávamos com a aplicação do guia no primeiro semestre do ano de 2020, todavia, devido às alterações sofridas no calendário escolar e adoção de um formato de ensino remoto, organizado pela Secretaria de Educação em diversas cidades brasileiras, os planos foram adiados para um momento posterior a esse cenário.

Esperamos que a proposta do guia-avaliativo aqui apresentado e descrito possa operar como uma ferramenta teórico-prática para a avaliação de crianças migrantes, em idade escolar no Brasil, e que possa auxiliar professores e gestores escolares.

\section{REFERÊNCIAS}

CABETE, Marta Alexandra. O processo de ensino-aprendizagem do português enquanto língua de acolhimento. Dissertação (Mestrado em Língua e Cultura Portuguesa) - Universidade de Lisboa, Lisboa, 2010.

CORDEIRO, E.N; BALDIN, F.D.C. O processo de formação inicial de professores de português para falantes de outras línguas na UTFPR-CT: integração entre prática pedagógica e teoria. Revista Línguas \& Letras, v. 18, n. 39, p. 96-111, 2017.

GROSSO, M.J.R. Língua de acolhimento, língua de integração. Horizontes de Linguística Aplicada, v. 9, n.2, p. 61-77, 2010.

LEFFA, V. J. Uma outra aprendizagem é possível: colaboração em massa, recursos educacionais abertos e ensino de línguas. Trabalhos em Linguística Aplicada. Campinas, nº 55/2, p. 353-377, 2016. Disponível em: https://bityli.com/oGGSA. Acesso em: 10 out. 2018.

MCLAUGHLIN, Barry; BLANCHARD, Antoinette Gesi; OSANAI, Yuka. Assessing Language Development in Bilingual Preschool Children. 22. ed. Washington, Dc: Office Of Bilingual Education And Minority Languages Affairs (Ed), 1995. 29 p. Disponível em: https://eric.ed.gov/?id=ED388088. Acesso em: 01 out. 2019.

NOGUEIRA, Maria das Dores Pimentel. Extensão Universitária no Brasil: uma Revisão Conceitual. In FARIA, Doris Santos de (org). Construção Conceitual da Extensão na América Latina.Brasília. Editora UNB. 2001.

NORTON, B. Identity and language learning: Extending the conversation. Multilingual matters, 2013.

OLIVEIRA, M. de. Imigrantes haitianos no Paraná em 2015. Refúgio e hospitalidade. Curitiba: Kairós, p. 249-276, 2016.

ORGANIZAÇÃO DAS NAÇÕES UNIDAS. Alto Comissariado das Nações Unidas para os Refugiados (ACNUR). Relatório "Refúgio no Brasil: uma análise estatística - Janeiro de 2010 a Outubro de 2014". Disponível em: http://www.acnur.org/t3/fileadmin/scripts/d 


\section{REVISTA DA ABRALIN}

oc.php?file=t3/fileadmin/Documentos/portugues/Estatisticas/Refugio_no_Brasil_2010_2014. Acesso em: 18 set. 2015.

ORGANIZAÇÃO DAS NAÇÕES UNIDAS. Alto Comissariado das Nações Unidas para Refugiados. Relatório Tendências Globais. Genebra: 2015. Disponível em http://http:// www.unhcr.org/2014trends Acesso em: 19 nov. 2015.

RETORTA, Miriam Sester; MAROCHI, Thaís Barbosa. Avaliação em línguas estrangeiras: da teoria à prática. Curitiba: CRV, 2018. 162 p.

RUSSO, Kelly; MENDES, L; Borri-Anadon, C. Crianças em situação de imigração na escola pública: percepções de professores/as. Cadernos de Pesquisa (FUNDAÇÃO CARLOS CHAGAS. IMPRESSO), v. 50, p. 256-272, 2020. 